rev Psi

Revista de Psicología (UNLP)

https://revistas.unlp.edu.ar/revpsi

\title{
Memoria emocional en niñas y niños preescolares de diferentes condiciones socio-ambientales
}

\author{
Verónica Adriana Ramírez ${ }^{1,2} \quad$ Eliana Ruetti ${ }^{1,2}$
}

Correspondencia

elianaruetti@gmail.com

Filiaciones institucionales

${ }^{1}$ Unidad de Neurobiolgía Aplicada, UNA, $\quad$ 2Facultad de Psicología (UBA, Argentina) CEMIC-CONICET (Argentina)

\section{Resumen}

La memoria de largo término de información con valencia positiva o negativa se denomina memoria emocional. Existen diversos factores individuales y socio-ambientales que se asocian a variaciones en la evocación de la memoria de niñas y niños preescolares. En este estudio se analizó el desempeño en una tarea de memoria emocional de niñas y niños de 4 años provenientes de hogares con diferentes condiciones socio-ambientales. Se comparó la información obtenida a través del recuerdo libre y el reconocimiento de las imágenes presentadas previamente. Se encontraron diferencias en el recuerdo libre de las imágenes negativas y en el total de las imágenes recordadas, donde las niñas recordaron mayor cantidad de imágenes, que los niños. No se encontraron diferencias en el reconocimiento de las imágenes en función del sexo de las/os participantes, aunque sí se encontró que el grupo con condiciones socio-ambientales desfavorables presentó mayor reconocimiento de imágenes neutras que el de condiciones favorables.

\section{Palabras clave}

memoria | emociones | niñas y niños | condiciones socio-ambientales | desarrollo

\section{Cómo citar}

Ramírez, V. A. y Ruetti, E. (2021). Memoria emocional en niñas y niños preescolares de diferentes condiciones socio-ambientales. Revista de Psicología, 20(1), 157-177. HTTPS://DX.DOI.ORG/10.24215/

$\begin{array}{ll}\text { Proceso editorial } \\ \text { Recibido } & \text { 1ra decisión } \\ 31 \text { mar. 2020 } & \text { 14 jul. 2020 } \\ \text { Aceptado } & \text { Publicado } \\ 3 \text { may. 2021 } & 6 \text { jun. 2021 }\end{array}$

Coordinadora del dossier

Marina Trakas (Instituto de Investigaciones Filosóficas, IIF-SADAF, Argentina)
ISSN

2422-572X

Licencia

Licencia de Cultura Libre CC-BY 4.0

(Compartir - Adaptar - Atribuir)

Entidad editora

RevPsi es una publicación de la

Facultad de Psicología (Universidad

Nacional de La Plata, Argentina) 


\title{
Memória emocional em crianças pré-escolares de diferentes condições socioambientais
}

\section{Resumo}

A memória de longo prazo de informações com diferentes valências (ou seja, positiva ou negativa) é chamada de memória emocional. Existem vários fatores individuais e socioambientais que estão associados a variações na evocação da memória pré-escolar. Neste estudo, foi analisado o desempenho em tarefa de memória emocional de meninas e meninos de 4 anos de idade, provenientes de lares com diferentes condições socioambientais. Foram comparadas as informações obtidas por meio de evocação livre e reconhecimento de imagens apresentadas anteriormente. Diferenças foram encontradas na memória livre de imagens negativas e no total de imagens lembradas, onde as meninas lembraram mais imagens, em comparação aos meninos. Não foram encontradas diferenças no reconhecimento das imagens de acordo com o gênero dos participantes, embora tenha sido verificado que o grupo com condições socioambientais desfavoráveis apresentou maior reconhecimento de imagens neutras do que o grupo com condições favoráveis.

\section{Palavras-chave}

memória | emoções | crianças | condições socioambientais | desenvolvimento

\section{Emotional memory in preschool children from different socio- environmental backgrounds}

\begin{abstract}
Long-term memory of information with different valences (i.e., positive, negative) is called emotional memory. Various individual and socio-environmental factors are associated with variations in young children's memory recall. In this study, the performance in an emotional memory task of 4-year-old girls and boys from homes with different socio-environmental conditions was analyzed. The information obtained through free recall and recognition of previously presented images was compared. Differences were found in the free memory of negative images and the number of remembered images: girls remembered more images compared to boys. No differences were found in the recognition of images based on the sex of the participants, although it was found that the group with unfavourable socio-environmental conditions presented greater recognition of neutral images than the group with favourable conditions.
\end{abstract}

\section{Keywords}

memory | emotions | children | socio-environmental conditions | development 


\section{Aspectos destacados del trabajo}

- La memoria emocional presenta variaciones en relación al contenido emocional de los estímulos empleados y al sexo de las/os participantes.

- Las variables de memoria emocional deben analizarse teniendo en cuenta la valoración de las niñas y los niños.

- Es importante incorporar variables complementarias en el estudio de la memoria emocional (recuerdo libre, reconocimiento).

- Las condiciones socio-ambientales modulan la memoria solo cuando la demanda de la tarea es baja.

Diversas investigaciones han estudiado la relación entre la memoria y las emociones. Las mismas proponen que existe una asociación significativa entre las emociones con las cuales se procesan los eventos y su recuerdo posterior y que aquellos eventos o experiencias emocionalmente significativos se retienen y recuerdan por extensos períodos de tiempo (Brainerd et al., 2010; Channell y Barth, 2013; Quas y Lench, 2007). El almacenamiento de la información emocional está acompañado por factores activantes de alarma o alerta que favorecen su evocación (e.g., Cordon et al., 2013). A este proceso se lo denomina memoria emocional (Cordon et al., 2013; Guzmán-Ramos et al., 2018; Siller-Pérez et al., 2019). En comparación con otros tipos de memoria, la emocional se caracteriza por ser de largo término, persistente, relativamente estable y porque su recuperación puede ser tanto explícita como implícita (Cocenas-Silva et al., 2013). Al igual que otros tipos de memoria, la memoria emocional es susceptible de ser modificada tanto por la influencia de factores internos o individuales, como por el contexto o las variaciones socioambientales. En particular, la emergencia y desarrollo de la memoria emocional comienza en fases tempranas, presentando cambios significativos a partir de la etapa preescolar (Bauer et al., 2012).

\section{Factores moduladores de la memoria emocional}

\section{Rol de la edad}

Existen diversos predictores confiables del rendimiento de la memoria. Uno de los principales es la edad, el cual ha sido estudiado en relación con la recuperación de información emocional (Goodman et al., 1997) y no-emocional (Courage y Cowan, 2008). Específicamente dentro del estudio de las experiencias emocionales, algunas investigaciones han analizado los factores involucrados en la consolidación y la evocación de dichas experiencias durante el desarrollo (Cordon et al., 2013; 
Leventon et al., 2014; Solomon et al., 2012). En este sentido, se ha comprobado que en las niñas y los niños la edad es un factor que influye en estas memorias, encontrándose marcadas diferencias entre la cantidad de información recordada y en la precisión con que lo hacen (Brainerd et al., 2010; Langnes et al., 2019; Leventon et al., 2014). Por ejemplo, a los 4 y 5 años, las niñas y los niños pueden codificar y evocar información emocional más específica e integrada, en comparación con las/os de 3 años (Brainerd et al., 2008; Wang, 2008).

Los cambios en la memoria relacionados con la edad se documentaron utilizando una variedad de paradigmas. Davidson et al. (2001) encontraron un mayor reconocimiento de relatos de acciones positivas y negativas en comparación con el reconocimiento de relatos no-emocionales. Esto se constata tanto en la evocación inmediata como después de un intervalo de 24 horas en niñas y niños de 7 a 11 años. Este patrón de resultados estuvo presente en todas las edades. Resultados similares se observaron cuando el intervalo de tiempo entre la presentación de la tarea y la evocación fue mayor (una semana) y con estímulos visuales, ya que tanto niñas y niños ( 8 a 12 años) como adultas/os reconocieron más imágenes negativas que neutras (Cordon et al., 2013). Quas y Lench (2007) observaron en niñas y niños de 5 a 6 años que el recuerdo libre de videos que provocaban miedo, luego de un intervalo de una semana, correlacionó positivamente con la excitación fisiológica que presentaron durante la visualización de los mismos. Sin embargo, los estudios de Cordon et al. (2013) y de Quas y Lench (2007) no incluyeron el desempeño de la memoria ante estímulos positivos, proporcionando solo una visión parcial de la memoria emocional en las niñas y los niños.

$\mathrm{Al}$ analizar el papel de la activación sobre la memoria emocional, Leventon y colegas (2014) encontraron que niñas y niños de 5 a 8 años consideraron más activantes las imágenes positivas y negativas que las neutras, pero no se encontraron diferencias entre los grupos de edad. Por otro lado, luego de un intervalo de 24 horas, las niñas y los niños mayores reconocieron más cantidad de imágenes negativas en comparación con las positivas, mientras que las/os más pequeña/os no mostraron este efecto. En el estudio mencionado, a pesar de que las valoraciones de los estímulos fueron similares a las de participantes adultas/os de otras investigaciones, se constató un procesamiento emocional diferencial de los estímulos a través de las respuestas fisiológicas de las niñas y los niños, el cual podría estar explicando los efectos diferenciales en la modulación de la valencia sobre la memoria en las diferentes edades (Leventon et al., 2014).

El tipo de estímulos empleado en las tareas también podría modular el desempeño de la memoria. En ese sentido, Massol y colaboradores (2020) encontraron un mejor desempeño en las niñas y los niños de 8 a 11 años al evaluar la memoria episódica, como resultado de la modulación de la valencia de los estímulos y esta mejora sería similar a la observada en adultas/os. Sin embargo, este efecto variaba si se utilizaban como estímulos imágenes o palabras, ya que las niñas y los niños exhibieron un sesgo emocional positivo ante las palabras, encontrándose una mejora tanto en el recuerdo 
y en la memoria asociativa, independientemente de la información contextual. Por otro lado, las/os adulta/os recordaron mejor las imágenes negativas y positivas, mientras que las niñas y los niños presentaron una memoria mayor solo para las imágenes negativas (Massol et al., 2020).

En síntesis, durante los últimos años se llevaron a cabo investigaciones que presentaron variaciones en las edades de las/os participantes, en los diferentes componentes de la tarea (Cordon et al., 2013; Eissen et al., 2019), en los intervalos de tiempo entre la presentación de los estímulos y la evocación de la memoria (Leventon et al., 2014) en la cantidad y el tipo de estímulos presentados (Channell y Barth, 2013; Van Bergen et al., 2015), en las medidas elegidas para evaluar la evocación de la memoria y en las variables conductuales, autonómicas o neurofisiológicas asociadas al desempeño (Raffington et al., 2020; Stenson et al., 2019).

\section{Rol de la valencia y la activación}

Además de la edad, otros dos factores relevantes en la modulación de la memoria emocional son la valencia de los estímulos y el grado de activación producido por los mismos (Kuppens et al., 2013), ya que incidirían en el almacenamiento posterior dentro de un sistema de memoria más permanente. Ambos factores se encuentran implicados en la valoración emocional, que puede definirse como el proceso a través del cual se generan diferentes respuestas ante un estímulo a partir de evaluaciones subjetivas (Fernando et al., 2017; Parsafar y Davis, 2018; Scherer y Fontaine, 2018). La valoración emocional se refiere a la información que confiere un significado personal a los eventos percibidos, que se extrae de los estímulos ambientales y resulta de la interacción entre las propiedades de estos estímulos y de la sensibilidad individual ante los mismos (Ridderinkhof, 2017; Yih et al., 2018).

Las variaciones en la valencia explicarían por qué los eventos emocionalmente significativos se retienen de modo diferente que los sucesos neutros, si bien no siempre es clara la dirección en la cual se produce este efecto diferencial (Channell y Barth, 2013). Tanto la valencia como la activación de los estímulos aumentan la vivacidad de la información (Kensinger y Corkin, 2003, 2004). Por ejemplo, los estímulos emocionales resultan más novedosos, distintivos, llamativos y significativos que los neutros (Öhman et al., 2001). Por otra parte, dichos estímulos emocionales son más propensos a activar la información semántica y a involucrar procesos de interpretación, en comparación con los estímulos no-emocionales (Brainerd et al., 2010).

En este sentido, Van Bergen et al. (2015) evaluaron el recuerdo diferido de experiencias cotidianas que se presentaban a través de relatos breves. Se halló que niñas y niños de 5 y 6 años recordaban mejor los relatos emocionales que los neutros y específicamente que los relatos negativos se recordaban mejor que los positivos. En un estudio previo de nuestra autoría, encontramos que la valoración emocional en niñas y niños de 4 años no coincidía con la valencia de la tarea y que las niñas y los niños de 5 años mostraron mayores acuerdos en la valoración emocional (Jaume et 
al., 2016). Por otro lado, los resultados señalan un desempeño diferencial cuando se analiza la memoria teniendo en cuenta la valoración propia de cada niña y niño, en comparación con la valoración inherente a los estímulos que componen la tarea (Ruetti et al., 2019). En este sentido, aunque se encontró una prevalencia de los recuerdos negativos, el desempeño fue mayor al evaluar la memoria teniendo en cuenta la valoración emocional de las niñas y los niños, en lugar de la valencia de la tarea. Debido a ello, se enfatizó la necesidad de incorporar la información proveniente de la valoración emocional al analizar el desempeño de las niñas y los niños en esa etapa del desarrollo. En el presente trabajo se sostiene dicho abordaje metodológico del desempeño de la memoria emocional.

Por otro lado, el grado de activación que produce una emoción también incide en la memoria emocional. Esto implica que dada una experiencia con una valencia emocional positiva o negativa, puede variar la intensidad que ese contenido genere (Stenson et al., 2019). El presente trabajo se limita a abordar el papel de diferentes valencias sobre el recuerdo posterior; no se analiza la dimensión de activación de los estímulos empleados y su interacción con la valencia.

\section{Rol de las diferencias de sexo}

Al considerar posibles diferencias individuales en el procesamiento emocional, podría señalarse al sexo de las/os participantes como un factor modulador de su desempeño. En estudios realizados en adultas/os, se verificó una mayor reactividad de la amígdala ante imágenes amenazantes en mujeres que en hombres (Canli et al., 2002). Esta reacción también se encontró en el reconocimiento de expresiones emocionales en mujeres con trastornos de ansiedad (Ohrmann et al., 2010). Además, en cuanto a la valoración emocional, hay una mayor tendencia de las mujeres a valorar las imágenes negativas como tales, en comparación con los hombres (Bradley y Lang, 2000).

Los estudios realizados en niñas y niños encuentran un patrón de respuesta similar. Por ejemplo, al investigar los factores fisiológicos implicados en este procesamiento (como la conductancia de la piel y el shock impulsado por el miedo), se encontró que las niñas de 7 a 10 años fueron más sensibles para iniciar una movilización defensiva fisiológica que los niños (McManis et al., 2001). Esto podría deberse a que también tendieron a valorar más imágenes negativas como tales.

Respecto al desarrollo del reconocimiento emocional de expresiones faciales, se identificó un efecto del sexo en participantes de 4 a 9 años, con un mayor reconocimiento en las niñas que en los niños (Widen y Russell, 2010). En otro estudio similar en el que se analizó el reconocimiento de expresiones de diferente intensidad desde los 4 a los 18 años de edad, se encontró que las niñas reconocieron con mayor precisión las expresiones faciales que los niños, especialmente las de ira y asco (Montirosso et al., 2010) y que este reconocimiento se incrementaba con la edad.

Por otra parte, los estudios orientados a analizar las diferencias de sexo sobre el 
recuerdo de experiencias emocionales durante el desarrollo, se centraron en investigar el papel del estrés sobre la evocación de estas memorias. En ese sentido, existe evidencia que sugiere que las niñas son más reactivas al estrés agudo que los niños (Hostinar et al., 2015; Raffington et al., 2018; Räikkönen et al., 2010; Quas et al., 2016). Específicamente, la memoria de niñas de 6 y 7 años acerca de la información negativa estuvo fuertemente modulada por la experiencia de estrés y la respuesta de cortisol asociada, en comparación con los niños (Raffington et al., 2020).

\section{Rol de las variaciones socio-ambientales}

Los mecanismos por los cuales las condiciones socio-ambientales pueden afectar las prácticas de crianza y el desarrollo de los procesos cognitivos incluyen fundamentalmente a la educación materna, la salud mental de madres y padres (trastornos depresivos, de ansiedad y sociales), el estrés familiar, la disponibilidad de redes sociales de soporte, la cantidad y calidad de estimulación para el aprendizaje en los hogares y las características del temperamento de las niñas y los niños (Bradley y Corwyn, 2002; Gershoff et al., 2010; Hughes et al., 2009). En forma complementaria, diferentes investigaciones dan cuenta de que las respuestas a las situaciones de estrés son uno de los mediadores significativos del efecto del ambiente sobre el desarrollo cognitivo, así como también de las oportunidades de adquisición de aprendizajes desde la etapa preescolar (Blair et al., 2011; Shonkoff et al., 2012).

Existen estudios que analizan el desempeño en tareas cognitivas de poblaciones vulnerables, en los cuales se encontraron diferencias en las habilidades secuenciales a los 4 y 5 años (Lacunza et al., 2010) y en una tarea de memoria de trabajo verbal en niñas y niños de 8 años (Ruiz y Del Río, 2012) en función de los niveles de pobreza. Previamente, las autoras del presente trabajo realizaron un estudio en el cual compararon el desempeño en una tarea de memoria emocional de preescolares, analizando el papel de las variaciones socio-ambientales (Ruetti et al., 2019) y no se hallaron diferencias entre las niñas y niños provenientes de hogares con condiciones socio-ambientales favorables y desfavorables. Una particularidad de ese estudio es que se caracterizó la memoria emocional en función de la cantidad de imágenes evocadas libremente. En el actual trabajo, considerando los resultados previos, se comparará el desempeño a través de dos formas de evaluación que dan cuenta de la expresión de la memoria emocional: el recuerdo libre y el reconocimiento de imágenes con diferente valencia. Esta última modalidad de evaluación implica la obtención de información con menos demanda cognitiva por parte de las niñas y los niños. Se espera que esto facilite la expresión de las memorias en niñas y niños de 4 años, ya que a esta edad estudios previos reportan que presentan menos evocación en esta tarea, fuertemente influenciada por las habilidades lingüísticas (Ruetti et al., 2019).

En función de lo desarrollado, el objetivo principal de este trabajo fue analizar el desempeño en una tarea de memoria emocional de niñas y niños de 4 años provenientes de hogares con diferentes condiciones socio-ambientales. Para ello, se evaluó el desempeño en una tarea de memoria emocional a través del recuerdo libre 
y el reconocimiento de imágenes con diferente valencia y se compararon las variaciones obtenidas en función del sexo y de las condiciones socio-ambientales favorables y desfavorables de los hogares.

Una hipótesis de este trabajo es que las imágenes con valencia positiva y negativa se recordarán más que las imágenes neutras. En este sentido, se predice que las niñas presentarán mayor recuerdo de las imágenes con valencia emocional, en comparación con los niños y que el grupo con condiciones socio-ambientales favorables presentará mejor desempeño de memoria que el grupo con condiciones socio-ambientales desfavorables. Finalmente, los dos procedimientos propuestos para recuperar la memoria emocional (recuerdo libre y reconocimiento) mostrarán diferentes desempeños. Específicamente, se espera un mejor desempeño en la tarea de reconocimiento en comparación con la de recuerdo libre. Además, se estipula que la prueba de reconocimiento permitirá evidenciar variaciones en el desempeño de los distintos grupos, que no se expresarán en la tarea de recuerdo libre.

\section{Método}

\section{Participantes}

Se conformó una muestra de 32 participantes (20 niñas y 12 niños) de 4 años de edad y de diferentes condiciones socio-ambientales, que asistían a un jardín de infantes de gestión pública de la región sur de la Ciudad Autónoma de Buenos Aires. Las niñas y los niños incluidas/os en la muestra no tenían trastornos del desarrollo en términos de su historial de salud perinatal y postnatal, de acuerdo a lo manifestado por sus familias durante las entrevistas realizadas.

\section{Consideraciones éticas}

Se obtuvieron los consentimientos informados de madres/padres. Las tareas y procedimientos empleados fueron aprobados por el Comité de Ética de CEMIC (Protocolo $\mathrm{N}^{\circ}$ 961). El estudio se realizó de acuerdo con las normas éticas de la Asociación Americana de Psicología y con las leyes internacionales y nacionales de derechos del niño.

\section{Tarea y procedimiento de evaluación}

En este estudio se administró una tarea de memoria emocional que incluía dos componentes (Ruetti et al., 2019). Los componentes se administraron en dos sesiones de aproximadamente 20 minutos cada una. En la primera sesión, se administró el componente de valoración emocional y en la segunda se administró el componente de memoria emocional (test).

Componente de valoración emocional. Este componente evaluaba la atribución de tres posibles expresiones emocionales a imágenes con diferente valencia. El instrumento constaba de dos conjuntos de estímulos. El primer conjunto estaba compuesto por 
15 imágenes con diferente valencia (cinco negativas, cinco positivas y cinco neutras) que se obtuvieron del Sistema de Fotografías Afectivas para el Desarrollo para niñas y niños (DAPS, por sus siglas en inglés; Cordon et al., 2013). Todas las imágenes eran a color, tenían personas (por ejemplo, niñas, niños, mujeres), animales (por ejemplo, perros, cucarachas), objetos (por ejemplo, libro, taza) o personas que realizaban acciones (por ejemplo, niñas o niños jugando con una pelota, niña saltando la soga). Estas imágenes estaban contrabalanceadas de acuerdo a su valencia y se presentaron en una tablet o notebook. El segundo conjunto consistía en tres imágenes (en blanco y negro) con expresiones emocionales (caras felices, tristes o neutras) que las niñas y los niños tenían disponibles para realizar la valoración. Las niñas y los niños observaban las imágenes del primer conjunto y luego tenían que elegir una expresión del segundo conjunto para responder a la consigna: “ ¿Cómo te sentís cuando mirás esta imagen?". Cada imagen permanecía en la pantalla hasta que eligieran una expresión emocional (caras del segundo conjunto) y decidieran continuar con la tarea. Por este motivo, el tiempo de duración variaba entre las/os participantes, aunque su duración aproximada fue de dos segundos. La elección se hacía señalando una de las tres caras con expresiones emocionales del segundo conjunto (Figura 1). Antes de comenzar la tarea, las/os participantes observaban dos imágenes de ejemplo para constatar la comprensión de la consigna.

Las variables de interés fueron (a) la cantidad de respuestas de valoración emocional de las imágenes de cada valencia (negativa, positiva y neutra), definida como las atribuciones de valencia a cada imagen, que podía tomar valores entre 0 y 15 (total de imágenes de la tarea); y (b) la cantidad de acuerdos en la valoración emocional, definida como la comparación entre las respuestas de valoración de cada niña y niño y la valencia de cada imagen, que podía tomar valores de 0 a 5 , para cada valencia (negativa, positiva y neutra), por ejemplo 0 si la valencia otorgada no coincidía en ningún caso con la de las imágenes; o 5 si coincidían en las 5 imágenes de una valencia determinada.

Componente de memoria emocional. En este componente, se pedía a las niñas y los niños que evocaran inmediatamente las imágenes del primer conjunto descritas anteriormente (esta variable se obtuvo para controlar que codificaran la información visual pero no se incorporó como una variable de interés en el estudio). Después de un intervalo de 7-10 días, nuevamente se les pidió que evocaran esas imágenes (test). El test consistía en dos fases: (1) la fase de evocación libre, donde las/os participantes referían con palabras o frases a las imágenes que habían observado durante la tarea. Las variables de interés fueron el recuerdo libre de las imágenes negativas, positivas o neutras, definidas como la cantidad de imágenes evocadas de cada valencia. (2) la fase de reconocimiento, donde las/os participantes indicaban si las imágenes observadas previamente se encontraban entre un conjunto de 30 imágenes que se les presentaba en el test. Si la imagen elegida coincidía con la presentada previamente, se consideraba correcta. Las variables de interés fueron el reconocimiento de las imágenes negativas, positivas o neutras, definidas como la cantidad de imágenes 
reconocidas correctamente de cada valencia. Las variables obtenidas en las dos fases del test de memoria se calcularon teniendo en cuenta las respuestas que cada niña y niño había dado en el componente de valoración emocional, por ejemplo, si un/a participante evocaba la imagen de "una cucaracha", esta imagen se consideraba negativa, neutra o positiva de acuerdo a la valoración que había otorgado previamente. De esta manera, en las variables del componente de memoria emocional se consideraron las diferencias individuales provenientes de las variaciones en la valoración emocional. Como se mencionó previamente, este abordaje fue propuesto como una alternativa metodológica necesaria al momento de realizar las evaluaciones en una población infantil (Ruetti et al., 2019).

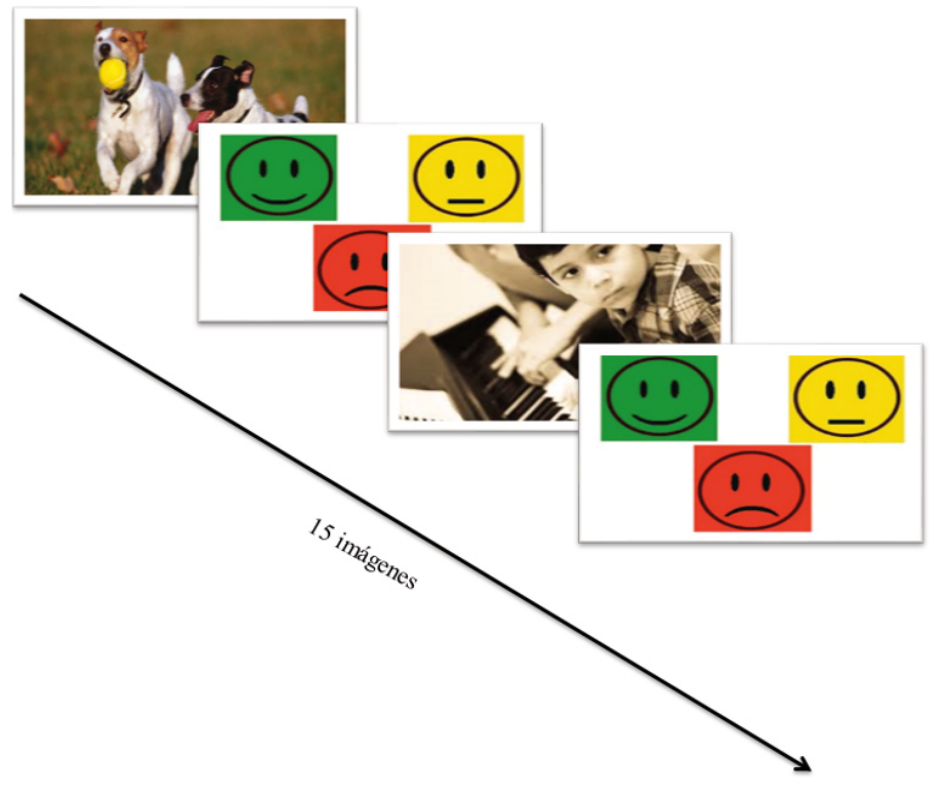

Figura 1. Ilustración del componente de valoración emocional

\section{Caracterización de las condiciones socio-ambientales}

Se utilizó un cuestionario para obtener información sobre las condiciones socioambientales a través de entrevistas individuales realizadas con las familias. Este cuestionario fue similar al utilizado en estudios previos en Argentina (Lipina et al., 2004; Segretin et al., 2014) y a través del mismo se obtuvo información de los niveles educativos y ocupacionales de las/os madres/padres, de las características de la vivienda y de las condiciones de hacinamiento del hogar. En el caso de las puntuaciones de los niveles educativos y ocupacionales de madres y padres, solo se consideró la puntuación más alta de ambos para obtener las puntuaciones totales. Dentro de las condiciones socio-ambientales, se caracterizó a la vivienda según su tipo, piso, agua, baño, techo, paredes externas y propiedad del hogar. Estos indicadores podían presentar diferentes puntuaciones. En la Tabla 1 se puede observar la caracterización de ambos grupos a través de los valores medios y desvíos estándar de las variables. Los valores medios permiten comparar en qué casos los indicadores 
presentaron puntuaciones más bajas, considerando que puntuaciones más altas correspondían a mejores condiciones (Segretin et al., 2014). A su vez, dentro de cada indicador se consideró si la caracterización señalada por la familia correspondía a una necesidad básica insatisfecha (e.g. madre o padre con primaria incompleta o desempleados, vivienda con baño compartido, mayor cantidad de personas habitando en el hogar que habitaciones disponibles). Se consideró que las familias tenían condiciones socio-ambientales desfavorables ante la presencia de por lo menos una de estas características. De esta manera, quedaron conformados dos grupos con condiciones socio-ambientales favorables $(n=11)$ y desfavorables $(n=19)$.

\begin{tabular}{lcrrr} 
& \multicolumn{2}{c}{ Desfavorables } & \multicolumn{2}{c}{ Favorables } \\
\cline { 2 - 5 } & $M$ & $D E$ & $M$ & $D E$ \\
\hline Educación & $07.11^{\mathrm{a}}$ & 02.05 & 06.55 & 02.95 \\
Ocupación & 03.84 & 01.21 & 05.18 & 02.64 \\
Vivienda $^{\mathrm{b}}$ & 10.74 & 01.52 & 12.00 & 00.00 \\
Hacinamiento $^{\mathrm{c}}$ & 07.26 & 02.51 & 07.36 & 01.57
\end{tabular}

Nota. M: Media. DE: Desvío estándar. Puntuaciones obtenidas del cuestionario NES administrado en las entrevistas. El tamaño de la muestra ( $n$ $=30$ ) es menor que la muestra total $(n=32)$, debido a que no se pudieron realizar las entrevistas con las familias de esa/os participantes. ${ }^{\text {aNivel }}$ secundario incompleto. ${ }^{b}$ Escala con un rango de 3-12 puntos, puntajes altos para mejores condiciones de vivienda. 'Escala con un rango de 0-9 puntos, puntajes altos para mejores condiciones.

Tabla 1. Valores medios y desvíos estándar de las puntuaciones de educación, ocupación, vivienda y hacinamiento de las condiciones socio-ambientales

\section{Análisis de los datos}

Nueve casos fueron excluidos de la muestra en la fase de reconocimiento por responder de igual manera a todas las imágenes, es decir, tanto por afirmar reconocer todas las imágenes o no haber reconocido ninguna. Por otro lado, no pudieron obtenerse los datos acerca de las condiciones socio-ambientales de dos de las/os participantes. Se realizaron análisis univariados de las variables de interés, que incluyeron la media, la mediana, la desviación estándar, el error estándar y el tamaño de la muestra para cada grupo, en función del sexo y las condiciones socioambientales de las/os participantes. Luego, se evaluaron la normalidad y la homocedasticidad de las variables a través de las pruebas de Shapiro-Wilk y Levene. Cuando no se cumplieron los requisitos paramétricos, se aplicaron transformaciones trigonométricas a las variables y los supuestos se volvieron a probar con las variables transformadas. Se utilizaron estadísticos no paramétricos al no verificarse el cumplimiento de los supuestos. Se utilizó la prueba de U de Mann-Whitney para comparar el desempeño de las variables del componente de memoria emocional para las tres valencias considerando el sexo (femenino, masculino) y las condiciones socio-ambientales (favorables, desfavorables) como variables de agrupación. Los 
análisis inferenciales se realizaron utilizando el software SPSS (versión 21.0).

\section{Resultados}

Se analizaron las respuestas de valoración de las/os participantes durante la presentación de las imágenes. Las niñas y los niños presentaron más respuestas de valoración positivas en comparación con las negativas y las neutras. Por otro lado, se consideraron los acuerdos en la valoración de las imágenes, en donde las/os participantes del estudio respondieron de manera diferencial ante las valencias de las imágenes. En este caso, nuevamente los acuerdos en la valoración fueron mayores para las imágenes positivas, en comparación con las negativas y las neutras (Tabla 2).

Posteriormente, al tomar sexo como variable de agrupación, se encontraron diferencias en el recuerdo libre total $(U=74.00, Z=-2.22, p=.028)$ y en el recuerdo libre de las imágenes negativas ( $U=66.00, Z=-2.67, p=.008$ ). La Figura 2 muestra que, tanto en el total como en las imágenes negativas, las niñas recordaron mayor cantidad de imágenes que los niños. Por otro lado, cuando se consideró el recuerdo libre tomando la variable condiciones socio-ambientales como variable de agrupación, no se encontraron diferencias significativas en la evocación de ambos grupos ( $p>.05)$.

Un análisis similar se realizó con la variable de reconocimiento. No se encontraron diferencias en esta variable en función del sexo de las/os participantes $(p>.05)$. Sin embargo, al considerar los grupos en función de las condiciones socio-ambientales, se encontró que el grupo con condiciones desfavorables presentó mayor reconocimiento de las imágenes neutras $(Z=-2.23, p=.029)$ (Figura 3) y descriptivamente se halló un reconocimiento superior de las imágenes positivas y negativas (aunque no estadísticamente significativo), en comparación con los participantes del grupo de condiciones favorables.

\section{Discusión}

Existen factores individuales, como la edad y el sexo y factores socio-ambientales, como las condiciones de vida del hogar y las características de las familias, que se asocian a variaciones en la evocación de la memoria de niñas y niños en edad preescolar (Nieto et al., 2018; Ramírez et al., 2021). Particularmente, la valoración emocional de los estímulos está involucrada en cómo se codifica y posteriormente se almacena la memoria (Leventon et al., 2014; Ruetti et al., 2019). Este trabajo proporciona evidencia sobre aspectos tempranos del desarrollo de la memoria emocional, sobre la implicancia de la valoración emocional en este proceso y acerca del papel modulador de factores individuales y contextuales durante el desarrollo. Especialmente, se evaluó la memoria emocional en niñas y niños de 4 años, provenientes de hogares con variaciones socioambientales, comparando el desempeño obtenido a través de dos variables para evaluar la evocación en este paradigma.

En primer lugar, se analizó la valoración emocional que las/os preescolares 
realizaron de las imágenes con diferente valencia, en comparación con las valencias inherentes a las mismas. Al igual que en trabajos previos (Ramírez et al., 2021; Ruetti et al., 2019), se encontraron variaciones en los acuerdos en la valoración emocional y debido a ello, se incorporó la respuesta de valoración al evaluar el desempeño de memoria. En el test de recuerdo libre se encontraron diferencias en el desempeño en función de la valencia de las imágenes y del sexo de las/os participantes, donde las niñas evocaron mayor cantidad de imágenes en total y de negativas en particular, en comparación con los niños.

Por otro lado, no se encontraron diferencias en el desempeño, obtenido a través de este test, en función de las condiciones socio-ambientales de las/os participantes. Sin embargo, al analizar la memoria emocional a través del test de reconocimiento, que permite una recuperación de la memoria con menor demanda cognitiva gracias al empleo de claves facilitadoras, se encontraron variaciones en función de la valencia de las imágenes y de las condiciones socio-ambientales de las/os participantes. Esto se evidencia en que el grupo con condiciones socio-ambientales desfavorables presentó mayor un reconocimiento de imágenes neutras que el de condiciones favorables. Pero a través de este test, no se presentaron diferencias en el desempeño de memoria en función del sexo de las/os participantes.

\begin{tabular}{|c|c|c|c|c|c|c|c|c|c|c|c|c|}
\hline & \multicolumn{12}{|c|}{ Valencia } \\
\hline & \multicolumn{4}{|c|}{ Negativa } & \multicolumn{4}{|c|}{ Neutra } & \multicolumn{4}{|c|}{ Positiva } \\
\hline & $M$ & $M d n$ & $D E$ & RIQ & $M$ & $M d n$ & $D E$ & $R I Q$ & $M$ & $M d n$ & $D E$ & $R I Q$ \\
\hline Valoraciones & 4.69 & 5.00 & 1.55 & 1 & 4.97 & 5.00 & 1.82 & 2 & 5.34 & 5.00 & 1.79 & 2 \\
\hline Acuerdos & 2.50 & 2.00 & 1.05 & 1 & 2.47 & 2.50 & 1.16 & 1 & 3.06 & 3.00 & 1.24 & 2 \\
\hline
\end{tabular}

Nota. M: Media. Mdn: Mediana. DE: Desvío estándar. RIQ: Rango intercuartil.
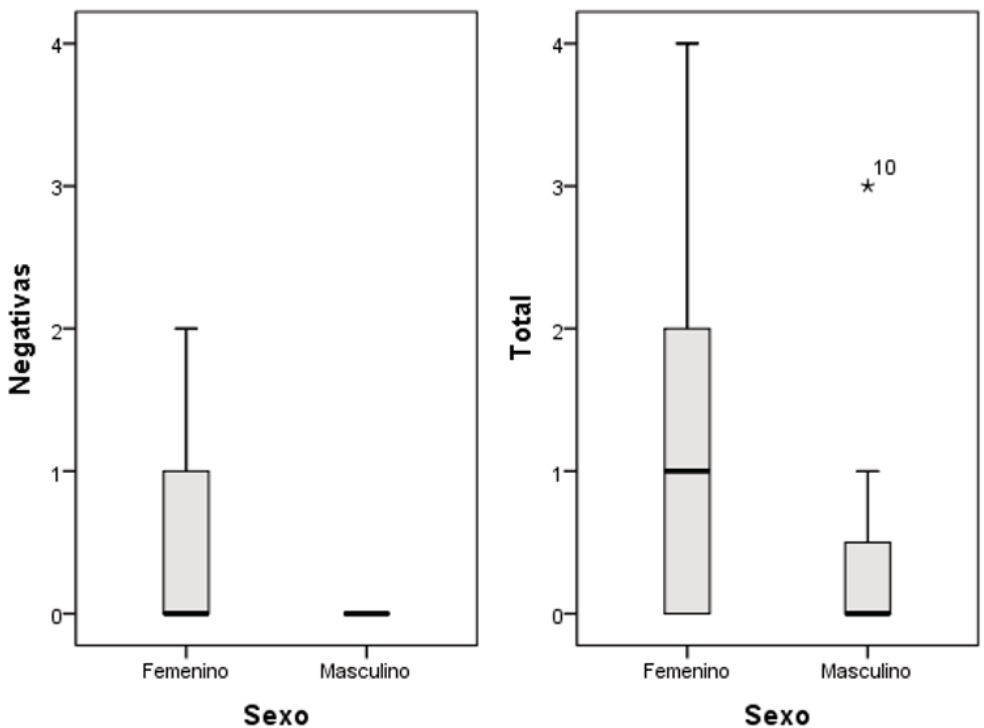

Figura 2. Comparación de la variable recuerdo libre de imágenes negativas y totales en función del sexo (femenino, masculino) de las/os participantes 


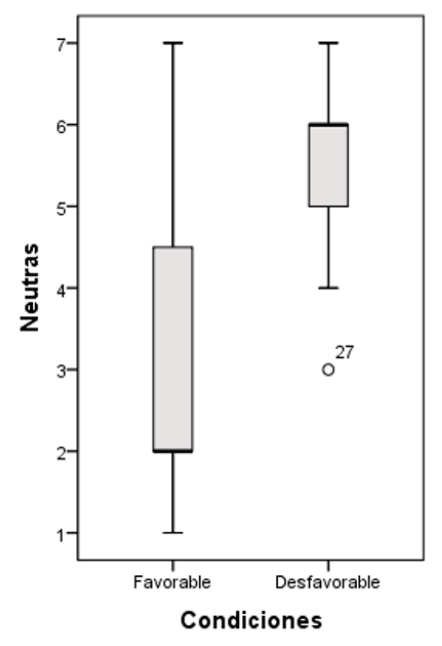

Figura 3. Comparación de la variable reconocimiento de imágenes negativas y totales en función de las condiciones socio-ambientales (favorables, desfavorables) de las/os participantes

En el mismo sentido que la literatura, estos hallazgos permiten vincular a la edad como un predictor fiable del desempeño de la memoria de información con diferente valencia (Baugerud y Melinder, 2012; Courage y Cowan, 2008). Las investigaciones que abordaron el papel de la edad sobre la memoria emocional en distintos momentos del desarrollo, encontraron que las imágenes aversivas se recordaron mejor que las neutras en niñas, niños y adultas/os (Cordon et al., 2013; Eisen et al., 2019). La semejanza entre el desempeño de niñas y niños (7 a 9 años) y adultas/os podría indicar que, en ese momento del desarrollo, ya se encuentran estabilizados los procesos de memoria de la información con diferente valencia.

De acuerdo a los hallazgos de estas investigaciones, la efectividad de las variables de memoria emocional podría considerarse específica del procedimiento empleado para su evaluación (Cordon et al., 2013; Eisen et al., 2019). Así, el test de recuerdo libre daría lugar a la aparición de errores o variaciones en el desempeño que no se presentaron al evaluar la memoria a través del reconocimiento. Esto es similar a lo que ocurre con la implementación de otros procedimientos, en los cuales el reconocimiento facilita la expresión de estas memorias. Por un lado, esto se observa en investigaciones realizadas en niñas y niños de menor edad, o en poblaciones con dificultades en las habilidades lingüísticas asociadas al desarrollo (Forrest et al., 2020). Por otro lado, al analizar la memoria emocional a través de los mismos estímulos, el mismo paradigma y los mismos análisis de datos en un estudio más abarcativo (con participantes de 8 a 30 años), se encontró que las imágenes negativas se recordaron mejor que las neutras y que la magnitud de esta diferencia disminuía en los hombres mayores, pero no en las mujeres mayores. Las imágenes positivas también se recordaron mejor que las neutras, pero este efecto fue menor y no varió en función de la edad o el sexo de las/os participantes (Stenson et al., 2019). Sin embargo, en el trabajo mencionado no se analizó cómo se expresa esa memoria en niñas y niños de menor edad. 
Existen varias explicaciones posibles para los hallazgos inconsistentes reportados que permiten analizar los resultados del actual trabajo. En los estudios mencionados, las determinaciones de la valencia y activación fueron hechas por las/os adultas/os (Bishop et al., 2004; Davidson et al., 2001; Moradi et al., 2000). Así, las niñas y los niños podrían no haber codificado ( $y$, por lo tanto, almacenado) los estímulos emocionales y neutros como tales. Estas implicancias metodológicas fueron abordadas previamente por las autoras en una investigación realizada en preescolares, a través de una tarea de memoria emocional utilizando imágenes con diferente valencia (Ruetti et al., 2019). En aquel estudio, se encontraron diferencias en el recuerdo libre y se planteó la inclusión de la valoración emocional como un componente importante en la evaluación de la memoria emocional en esta etapa de desarrollo. Esto interroga a los hallazgos previos en los cuales el proceso de valoración emocional no se tuvo en cuenta a nivel metodológico en las evaluaciones realizadas.

Por otra parte, el procesamiento emocional puede afectar la consolidación y recuperación de los recuerdos, especialmente la persistencia de los negativos. En este sentido, los eventos negativos provocaron más falsos recuerdos que los neutros en niñas y niños de 7 años (Otgaar et al., 2008); y la prevalencia de recuerdos negativos acerca de una experiencia dolorosa en niñas y niños, se asoció a una mayor intensidad del dolor y a un mayor estado de ansiedad durante esas experiencias (Noel et al., 2012a, 2012b). En el mismo sentido, las emociones influyeron en el reconocimiento de escenas negativas en niñas y niños en edad escolar (Cordon et al., 2013; Davidson et al., 2006; Leventon et al., 2014).

Además, los comportamientos de las/os preescolares pueden asociarse con diferentes aspectos de las condiciones socio-ambientales del hogar (Coke y Moore, 2017). Por ejemplo, las conversaciones sobre aspectos emocionales (Ornaghi et al., 2011; Rieffe y Wiefferink, 2017; Van Bergen y Salmon, 2010; Waters et al., 2019), los estilos de narración materna (Doan y Wang, 2010; Wang, 2019) y la cultura a la que pertenecen las niñas y los niños (Wang, 2008, 2019; Waters et al., 2019) son algunos de los factores que podrían estar relacionados con las respuestas emocionales. Estos estudios indican la relevancia de la interacción familiar y de los factores culturales en las experiencias personales y su posterior evocación. En el presente trabajo, se compararon niñas y niños con diferentes condiciones socio-ambientales. De la información proporcionada por las familias se obtuvieron los puntajes de las variables de educación y ocupación de las madres y los padres, de las características de las viviendas y del hacinamiento en el hogar, que los caracterizaron como desfavorables en función de obtener puntuaciones bajas en las variables mencionadas.

Las condiciones socio-ambientales del hogar se asociaron con las variaciones en la expresión de la memoria emocional de preescolares solamente cuando la misma fue evaluada a través del test de reconocimiento. No se encontró que un ambiente adverso (en función de las características indicadas) afectase a la expresión de la memoria emocional obtenida a través del recuerdo libre. Esto podría deberse a las diferentes demandas cognitivas de las fases del test, donde una alta demanda 
impediría la expresión de variaciones en el desempeño debido al efecto de piso evidenciado en todas/os las/os participantes (Whyte et al., 2017). Sin embargo, ante la fase del test con baja demanda (reconocimiento), se observó un patrón diferencial de respuesta hacia las imágenes neutras. El incremento en el reconocimiento de las imágenes podría explicarse porque la especial saliencia de los estímulos emocionales los vuelve más propensos a captar la atención y generar una activación que facilite su almacenamiento y posterior recuperación, efecto que no se observa frente a los estímulos no-emocionales (Pessoa et al., 2002). Pero en este caso, el reconocimiento del grupo de condiciones desfavorables también fue superior ante las imágenes positivas y negativas (aunque no significativamente).

De manera que el reconocimiento diferencial entre los grupos con distintas condiciones socio-ambientales podría estar relacionado con otros aspectos contextuales. Una posibilidad es pensar que el estrés puede afectar la recuperación de la memoria. Sin embargo, el papel del estrés sobre la memoria durante el desarrollo presenta hallazgos controversiales (Bremner y Narayan, 1998; Yuen et al., 2009), ya que se observan resultados diversos ante la exposición al mismo en diferentes períodos de la vida de una persona (Lupien et al., 2009). Por un lado, el estrés agudo facilita la memoria de trabajo en jóvenes (Lupien et al., 2002), donde los estímulos irrelevantes pueden ser percibidos como amenazantes, aumentando la atención dirigida hacia ellos y en consecuencia su recuerdo posterior (Lupien et al., 2009). Por otro lado, las situaciones de estrés elevado (hipercortisolemia) pueden deteriorar el recuerdo de los estímulos emocionales (Bremner y Narayan, 1998; Justel et al., 2013).

En ese sentido, las condiciones adversas, similares a las situaciones de estrés agudo, que se presentan en los hogares desfavorables podrían afectar las respuestas de las/os niñas/os (Lupien et al., 2002) generando un mayor reconocimiento de las imágenes. En un momento del desarrollo en el cual las respuestas de valoración emocional y de memoria emocional ya se encuentran en un nivel estable (sin fluctuaciones debidas a variaciones evolutivas), estas condiciones adversas aumentarían el valor de los estímulos de manera diferencial de acuerdo a la valencia de los mismos (esto es, potenciando las valencias emocionales, en comparación con las neutras; Ruetti et al., 2019). Sin embargo, cuando la categorización emocional aún es susceptible de ser modulada por las condiciones individuales y contextuales, esta atención se presentó diferencialmente orientada hacia las imágenes neutras (potenciando la valencia de los mismas). Es posible que esto sea a causa del valor adaptativo de identificar estímulos significativos durante una etapa del desarrollo donde las categorías emocionales aún no se encuentran consolidadas (Nelson y Russel, 2016). Estudios futuros deberían generarse para poner a prueba dicha hipótesis.

Dentro de las limitaciones que presenta este trabajo podemos señalar que no se analizó la dimensión de activación de las imágenes que observaron las niñas y los niños durante la tarea, de manera que se requieren estudios adicionales que analicen esta interacción entre las dimensiones de los estímulos y su efecto sobre el recuerdo posterior. Otro factor que podría afectar la interpretación de los resultados obtenidos 
se relaciona con el tamaño muestral reducido, que implicaría futuros estudios con muestras más grandes que permitiesen profundizar los efectos de las condiciones socio-ambientales desfavorables o adversas sobre la memoria emocional de las niñas y los niños. Un aspecto emergente de este trabajo es el efecto de piso encontrado en la variable de recuerdo libre. Una posible explicación de la baja cantidad de respuestas presentadas por las niñas y los niños (poco recuerdo) se relaciona con las dificultades en la expresión del lenguaje, estrechamente vinculadas a la expresión de la memoria (Floccia et al., 2020; Gathercole et al., 2019; Humphreys et al., 2020) y que no fueron analizadas en el estudio actual.

La relevancia de este trabajo consiste en señalar la comparación entre las dos formas de abordar la evaluación de la memoria emocional en preescolares y en enfatizar la necesidad de su implementación conjunta. La utilización de las variables de recuerdo libre y de reconocimiento podría contribuir a la exploración de potenciales variaciones en el desempeño, que serían el resultado de las condiciones socioambientales del hogar. De esta manera, una intervención sencilla en la forma de evaluación podría facilitar la expresión de esas memorias.

Adicionalmente, debido a la relación conocida entre las habilidades lingüísticas y la memoria (Fivush, 2019), este abordaje metodológico subsana las dificultades provenientes de evaluar únicamente la memoria a través de la expresión verbal de los recuerdos con diferente valencia y otorga mayor validez a los resultados obtenidos dado que permite aportar evidencia de un proceso cognitivo que de otra forma no sería posible recuperar. De la comparación de los resultados obtenidos entre las variables de recuerdo libre y de reconocimiento, se desprende que ambas contribuyen a la compresión de cómo se manifiesta la memoria emocional en la etapa preescolar. Aún aquellas niñas y niños que no expresaron ningún recuerdo durante la fase de recuerdo libre, pudieron reconocer las imágenes observadas previamente. Esto resalta la importancia de la incorporación de variables complementarias en la evaluación de la memoria emocional durante el desarrollo infantil.

\section{Referencias}

Bauer, P. J., Larkina, M. y Doydum, A. O. (2012). Explaining variance in long-term recall in 3-and 4year-old children: The importance of postencoding processes. Journal of Experimental Child Psychology, 113(2), 195-210. HTTPS://DOI.ORG/ 10.1016/J.JECP.2012.05.006.

Baugerud, G. A. y Melinder, A. (2012). Maltreated children's memory of stressful removals from their biological parents. Applied Cognitive Psychology, 26(2), 261-270. HTTPS://DOI.ORG/ 10.1002/ACP. 1817 .
Bishop, S., Dalgleish, T. y Yule, W. (2004). Memory for emotional stories in high and low depressed children. Memory, 12(2), 214-230. HTTPs:// DOI.ORG/10.1080/09658210244000667.

Blair, C., Granger, D. A., Willoughby, M., Mills-Koonce, R., Cox, M., Greenberg, M. T., Kivlighan, K. T., Fortunato, C. K. y FLP Investigators. (2011). Salivary cortisol mediates effects of poverty and parenting on executive functions in early childhood. Child Development, 82(6), 1970-1984. HTTPs://DOI.ORG/ 10.1111/J.1467-8624.2011.01643.X. 
Bradley, M. M. y Lang, P. J. (2000). Measuring emotion: Behavior, feeling, and physiology. In $\mathrm{R}$ Lane y L. Nadel (Eds.), Cognitive neuroscience of emotion (pp. 242-276). Oxford University Press.

Bradley, R. H. y Corwyn, R. F. (2002). Socioeconomic status and child development. Annual Review of Psychology, 53(1), 371-399. HTTPS://DOI.ORG/ 10.1146/ANNUREV.PSYCH.53.100901.135233.

Brainerd, C. J., Holliday, R. E., Reyna, V. F., Yang, Y. y Toglia, M. P. (2010). Developmental reversals in false memory: Effects of emotional valence and arousal. Journal of Experimental Child Psychology, 107(2), 137-154. HTTPs://DOI.ORG/ 10.1016/J.JECP.2010.04.013

Brainerd, C. J., Stein, L. M., Silveira, R. A., Rohenkohl, G. y Reyna, V. F. (2008). How does negative emotion cause false memories? Psychological Science, 19(9), 919-925. HTTPS://DOI.ORG/10.1111/ J.1467-9280.2008.02177.x

Bremner, J. D. y Narayan, M. (1998). The effects of stress on memory and the hippocampus throughout the life cycle: Implications for childhood development and aging. Development and Psychopathology, 10(4), 871-885. HTTPs:// DOI.ORG/10.1017/S0954579498001916

Canli, T., Desmond, J. E., Zhao, Z. y Gabrieli, J. D. (2002). Sex differences in the neural basis of emotional memories. Proceedings of the National Academy of Sciences, 99(16), 10789-10794. HTTPs:/ /DOI.ORG/10.1073/PNAS.162356599

Channell, M. M. y Barth, J. M. (2013). Individual differences in preschoolers' emotion content memory: The role of emotion knowledge. Journal of Experimental Child Psychology, 115(3), 552-561. HTTPS://DOI.ORG/10.1016/J.JECP.2013.01.012

Cocenas-Silva, R., Bueno, J. L. O. y Droit-Volet, S (2013). Emotion and long-term memory for duration: resistance against interference. Behavioural Processes, 97, 6-10. HTTPS://DOI.ORG/10.1016/J.BEPROC.2013.03.010

Cordon, I. M., Melinder, A. M., Goodman, G. S. y Edelstein, R. S. (2013). Children's and adults' memory for emotional pictures: Examining age-related patterns using the Developmental Affective Photo System. Journal of Experimental Child Psychology, 114(2), 339356. HTTPS://DOI.ORG/10.1016/J.JECP.2012.08.004

Courage, M. y Cowan, N. (Eds.). (2008). The development of memory in infancy and childhood. Psychology Press.

Davidson, D., Luo, Z. y Burden, M. J. (2001) Children's recall of emotional behaviours, emotional labels, and nonemotional behaviours: Does emotion enhance memory? Cognition and Emotion, 15(1), 1-26. HTTPS://DOI.ORG/10.1080/ 02699930125794
Davidson, M. C., Amso, D., Anderson, L. C. y Diamond, A. (2006). Development of cognitive control and executive functions from 4 to 13 years: Evidence from manipulations of memory, inhibition, and task switching. Neuropsychologia, 44(11), 2037-2078. H T T P S : / / D O I, O R G / $10.10016 /$ J.NEUROPSYCHOLOGIA.2006.02.006

Eisen, M. L., Goodman, G. S., Diep, J., Lacsamana, M. T., Olomi, J., Goldfarb, D. y Quas, J. A. (2019). Effects of interviewer support on maltreated and atrisk children's memory and suggestibility. International Journal on Child Maltreatment: Research, Policy and Practice, 2, 5578. HTTPS://DOI.ORG/10.1007/S42448-019-00016-7

Fernando, J. W., Kashima, Y. y Laham, S. M. (2017). Alternatives to the fixed-set model: A review of appraisal models of emotion. Cognition and Emotion, 31(1), 19-32. HTTPS://DOI.ORG/10.1080/ 02699931.2015 .1074548

Fivush, R. (2019). Sociocultural developmental approaches to autobiographical memory. Applied Cognitive Psychology, 33(4), 489-497. HTTPs:// DOI.ORG/10.1002/ACP.3512

Floccia, C., Delle Luche, C., Lepadatu, I., Chow, J., Ratnage, P. y Plunkett, K. (2020). Translation equivalent and cross-language semantic priming in bilingual toddlers. Journal of Memory and Language, 112, 104086. HTTPS://DOI.ORG/10.1016/ J.JML.2019.104086

Gathercole, S. E., Dunning, D. L., Holmes, J. y Norris, D. (2019). "Working memory training involves learning new skills": Corrigendum. Journal of Memory and Language, 106, 203. HTTPs:// DOI.ORG/10.1016/J.JML.2019.02.004

Gershoff, E. T., Grogan-Kaylor, A., Lansford, J. E., Chang, L., Zelli, A., Deater-Deckard, K. y Dodge, K. A. (2010). Parent discipline practices in an international sample: Associations with child behaviors and moderation by perceived normativeness. Child Development, 81(2), 487-502. HTTPS://DOI.ORG/ 10.1111/J.1467-8624.2009.01409.x

Goodman, G. S., Quas, J. A., Batterman-Faunce, J. M., Riddlesberger, M. M. y Kuhn, J. (1997). Children's reactions to and memory for a stressful event: Influences of age, anatomical dolls, knowledge, and parental attachment. Applied Developmental Science, 1(2), 54-75. HTTPS://DOI.ORG/10.1207/ S1532480XADSO102_1

Guzmán-Ramos, K., Venkataraman, A., Morin, J. P., Osorio-Gómez, D. y Bermúdez-Rattoni, F. (2018). Differential requirement of de novo Arc protein synthesis in the insular cortex and the amygdala for safe and aversive taste long-term memory formation. Behavioural Brain Research, 342, 89-93. HTTPS:/DOI.ORG/10.1016/J.BBR.2018.01.006 
Hostinar, C. E., Johnson, A. E. y Gunnar, M. R. (2015). Early social deprivation and the social buffering of cortisol stress responses in late childhood: An experimental study. Developmental Psychology, 51(11), $1597-$ 1608. HTTPS://DOI.ORG/10.1037/DEVOoOo029

Hughes, C., Ensor, R., Wilson, A. y Graham, A. (2009). Tracking executive function across the transition to school: A latent variable approach. Developmental Neuropsychology, 35(1), 20-36. HTTPS://DOI.ORG/ $10.1080 / 87565640903325691$

Humphreys, M. S., Li, Y. R., Burt, J. S. y Loft, S. (2020) How semantic processing affects recognition memory. Journal of Memory and Language, 113, 104109. HTTPS://DOI.ORG/10.1016/J.JML.2020.104109

Jaume, L. C., Ruetti, E. M., Segretin, M. S. y Lipina, S J. (2016). Efectos de la edad sobre la valoración emocional durante la etapa preescolar. Anuario de Investigaciones de la Facultad de Psicología Universidad de Buenos Aires, 23(2), 281-287.

Justel, N., Psyrdellis, M. y Ruetti, E. (2013) Modulación de la memoria emocional: una revisión de los principales factores que afectan los recuerdos. Suma Psicológica, 20(2), 163-174.

Kensinger, E. A. y Corkin, S. (2003). Memory enhancement for emotional words: Are emotional words more vividly remembered than neutral words? Memory \& Cognition, 31(8), 1169-1180. HTTPS://DOI.ORG/10.3758/BF03195800

Kensinger, E. A. y Corkin, S. (2004). Two routes to emotional memory: Distinct neural processes for valence and arousal. Proceedings of the National Academy of Sciences, 101(9), 3310-3315. HTTPS:// DOI.ORG/10.1073/PNAS.0306408101

Kuppens, P., Tuerlinckx, F., Russell, J. A. y Barrett, L. F. (2013). The relation between valence and arousal in subjective experience. Psychological bulletin, 139(4), 917. HTTPS://DOI.ORG/10.1037/A0030811

Lacunza, A. B., Contini, N. y Castro Solano, A. (2010) Las habilidades cognitivas en niños preescolares. Un estudio comparativo en un contexto de pobreza Acta Colombiana de Psicología, 13(1), 25-34.

Langnes, E., Vidal-Piñeiro, D., Sneve, M. H., Amlien, I. K., Walhovd, K. B. y Fjell, A. M. (2019). Development and decline of the hippocampal long-axis specialization and differentiation during encoding and retrieval of episodic memories. Cerebral Cortex, 29(8), 3398-3414. HTTPs:// DOI.ORG/10.1093/CERCOR/BHY209

Leventon, J. S., Stevens, J. S. y Bauer, P. J. (2014). Development in the neurophysiology of emotion processing and memory in school-age children. Developmental Cognitive Neuroscience, 10, 21-33. HTTPS://DOI.ORG/10.1016/J.DCN.2014.07.007
Lipina S. J., Martelli M. I., Vuelta B., Injoque-Ricle I. y Colombo J. A. (2004). Pobreza y desempeño ejecutivo en alumnos preescolares de la ciudad de Buenos Aires (Argentina). Interdisciplinaria, 21, 53-193.

Lupien, S. J., McEwen, B. S., Gunnar, M. R. y Heim, C. (2009). Effects of stress throughout the lifespan on the brain, behaviour and cognition. Nature Reviews Neuroscience, 10(6), 434-445. HтTPs:// DOI.ORG/10.1038/NRN2639

Lupien, S. J., Wilkinson, C. W., Brière, S., Ménard, C., Kin, N. N. Y. y Nair, N. P. V. (2002). The modulatory effects of corticosteroids on cognition: studies in young human populations. Psychoneuroendocrinology, 27(3), 401-416. HTTPS://DOI.ORG/10.1016/so3064530(01)00061-0

Massol, S., Vantaggio, S. y Chainay, H. (2020). Emotional Modulation of Episodic Memory in School-Age Children and Adults: Emotional Items and Their Associated Contextual Details. Journal of Experimental Psychology: General, 149(9), 16841703. HTTP://DX.DOI.ORG/10.1037/XGE0000744

McManis, M. H., Bradley, M. M., Berg, W. K., Cuthbert, B. N. y Lang, P. J. (2001). Emotional reactions in children: Verbal, physiological, and behavioral responses to affective pictures. Psychophysiology, 38(2), 222-231. нттPs:// DOI.ORG/10.1111/1469-8986.3820222

Montirosso, R., Peverelli, M., Frigerio, E., Crespi, M. y Borgatti, R. (2010). The development of dynamic facial expression recognition at different intensities in 4-to 18-year-olds. Social Development, 19(1), 71-92. HTTPS://DOI.ORG/10.1111/J.1467-9507.2008.00527.X

Moradi, A. R., Taghavi, R., Neshat-Doost, H. T., Yule, W. y Dalgleish, T. (2000). Memory bias for emotional information in children and adolescents with posttraumatic stress disorder: A preliminary study. Journal of Anxiety Disorders, 14(5), 521-534. HTTPS://DOI.ORG/10.1016/so887-6185(00)00037-2

Nelson, N. L. y Russell, J. A. (2016). Building emotion categories: Children use a process of elimination when they encounter novel expressions. Journal of Experimental Child Psychology, 151, 120130. HTTPS://DOI.ORG/10.1016/J.JECP.2016.02.012

Noel, M., Chambers, C. T., McGrath, P. J., Klein, R. M. y Stewart, S. H. (2012a). The influence of children's pain memories on subsequent pain experience. Pain $^{\oplus}$, 153(8), 1563-1572. HTTPS://DOI.ORG/ 10.1016/J.PAIN.2012.02.020

Noel, M., McMurtry, C. M., Chambers, C. T. y McGrath, P. J. (2012b). Children's memory for painful procedures: the relationship of pain intensity, anxiety, and adult behaviors to subsequent recall. Journal of Pediatric Psychology, 35(6), 626636. HTTPS://DOI.ORG/10.1093/JPEPSY/JSPO96 
Öhman, A., Flykt, A. y Esteves, F. (2001). Emotion drives attention: detecting the snake in the grass. Journal of Experimental Psychology: General, 130(3), 466-478. HTTPS://DOI.ORG/10.1037/0096-3445.130.3.466

Ohrmann, P., Pedersen, A., Braun, M., Bauer, J., Kugel, H., Kersting, A., Domschke, K., Deckert, J. y Suslow, T. (2010). Effect of gender on processing threatrelated stimuli in patients with panic disorder: sex does matter. Depression and Anxiety, 27(11), 10341043. HTTPS://DOI.ORG/10.1002/DA.20721

Otgaar, H., Candel, I. y Merckelbach, H. (2008) Children's false memories: Easier to elicit for a negative than for a neutral event. Acta Psychologica, 128(2), 350-354. HTTPS://DOI.ORG/ 10.1016/J.ACTPSY.2008.03.009

Parsafar P. y Davis E. L. (2018). Fear and anxiety. En H. Lench (Eds.), The function of emotions. HTTPs:// DOI.ORG/10.1007/978-3-319-77619-4_2

Pessoa, L., McKenna, M., Gutierrez, E. y Ungerleider, L. G. (2002). Neural processing of emotional faces requires attention. Proceedings of the National Academy of Sciences, 99(17), 11458-11463. HTTPs:/ /DOI.ORG/10.1073/PNAS.172403899

Quas, J. A., Rush, E. B., Yim, I. S., Edelstein, R. S. Otgaar, H. y Smeets, T. (2016). Stress and emotional valence effects on children versus adolescents' true and false memory. Memory, 24(5), 696-707. HTTPs:// DOI.ORG/10.1080/09658211.2015.1045909

Quas, J. A. y Lench, H. C. (2007). Arousal at encoding, arousal at retrieval, interviewer support, and children's memory for a mild stressor. Applied Cognitive Psychology: The Official Journal of the Society for Applied Research in Memory and Cognition, 21(3), 289-305. HTTPS://DOI.ORG/10.1002/ACP.1279

Raffington, L., Falck, J., Heim, C., Mather, M. y Shing, Y. L. (2020). Effects of stress on 6-and 7-year-old children's emotional memory differs by gender. Journal of Experimental Child Psychology, 199, 104924. HTTPs:// DOI.ORG/10.1016/J.JECP.2020.104924

Raffington, L., Prindle, J., Keresztes, A., Binder, J., Heim, C. y Shing, Y. L. (2018). Blunted cortisol stress reactivity in low-income children relates to lower memory function. Psychoneuroendocrinology, 90, 110-121 HTTPS://DOI.ORG/10.1016/J.PSYNEUEN.2018.02.002

Räikkönen, K., Matthews, K. A., Pesonen, A. K. Pyhälä, R., Paavonen, E. J., Feldt, K., Jones, A. Phillips, D. I. W., Seckl, J. R., Heinonen, K., Lahti, J., Komsi, N., Järvenpää, A. L., Eriksson, J., G. Strandberg, T. E. y Kajantie, E. (2010). Poor sleep and altered hypothalamic-pituitary-adrenocortical and sympatho-adrenal-medullary system activity in children. The Journal of Clinical Endocrinology \& Metabolism, 95(5), 2254-2261. HTTPs:// DOI.ORG/10.1210/JC.2009-0943
Ramírez, V. A., Lipina, S. J. y Ruetti, E. (2021). Individual and socioenvironmental differences in autobiographical emotional appraisal of preschoolers. Journal of Experimental Child Psychology, 201, 104982. HTTPs://DOI.ORG/ 10.1016/J.JECP.2020.104982

Ridderinkhof, K. R. (2017). Emotion in action: A predictive processing perspective and theoretical synthesis. Emotion Review, 9(4), 319-325. HтTPs:// DOI.ORG/10.1177/1754073916661765

Ruetti, E., Segretin, M. S., Ramírez, V. A. y Lipina, S. J. (2019). Role of emotional appraisal in episodic memory in a sample of Argentinean preschoolers. Frontiers in Psychology, 10, 2556. HTTPS://DOI.ORG/10.3389/FPSYG.2019.02556

Ruiz, N. C. y Del Río, P. (2012). Memoria de trabajo verbal y su relación con variables sociodemográficas en niños colombianos. Acta Colombiana de Psicología, 15(1), 99-109

Scherer, K. R. y Fontaine, J. R. (2018). The semantic structure of emotion words across languages is consistent with componential appraisal models of emotion. Cognition and Emotion, 33, 673-682. HTTPS://DOI.ORG/10.1080/02699931.2018.1481369

Segretin, M. S., Lipina, S. J., Hermida, M. J., Sheffield, T., Nelson, J. M., Espy, K. A. y Colombo, J. A (2014). Predictors of cognitive enhancement after training in a sample of Argentinean preschoolers from diverse socioeconomic backgrounds. Frontiers in Developmental Psychology, 13, A205. HTTPS://DOI.ORG/10.3389/FPSYG.2014.00205

Shonkoff, J. P., Richter, L., van der Gaag, J. y Bhutta, Z. A. (2012). An integrated scientific framework for child survival and early childhood development. Pediatrics, 129(2), e460-e472. HTTPS://DOI.ORG/10.1542/PEDS.2011-0366

Siller-Pérez, C., Fuentes-Ibañez, A., Sotelo-Barrera, E. L., Serafín, N., Prado-Alcalá, R. A., Campolongo, P., Roozendaal, B. y Quirarte, G. L. (2019). Glucocorticoid interactions with the dorsal striatal endocannabinoid system in regulating inhibitory avoidance memory. Psychoneuroendocrinology, 99, 97-103. HTTPS://DOI.ORG/10.1016/ J.PSYNEUEN.2018.08.021

Solomon, B., DeCicco, J. M. y Dennis, T. A. (2012). Emotional picture processing in children: an ERP study. Developmental Cognitive Neuroscience, 2(1), 110-119. HTTPS://DOI.ORG/10.1016/ J.DCN.2011.04.002

Stenson, A. F., Leventon, J. S. y Bauer, P. J. (2019). Emotion effects on memory from childhood through adulthood: Consistent enhancement and adult gender differences. Journal of Experimental Child Psychology, 178, 121-136. HTTPs://DOI.ORG/ 10.1016/J.JECP.2018.09.016 
Van Bergen, P., Wall, J. y Salmon, K. (2015). The good, the bad, and the neutral: The influence of emotional valence on young children's recall. Journal of Applied Research in Memory and Cognition, 4, 29-35. HTTPS://DOI.ORG/10.1016/ J.JARMAC.2014.11.001

Wang, Q. (2008). Emotion knowledge and autobiographical memory across the preschool years: A cross-cultural longitudinal investigation. Cognition, 108(1), 117-135. HTTPs://DOI.ORG/ 10.1016/J.COGNITION.2008.02.002

Whyte, A. R., Schafer, G. y Williams, C. M. (2017). The effect of cognitive demand on performance of an executive function task following wild blueberry supplementation in 7 to 10 years old children. Food \& Function, 8(11), 4129-4138. HTTPS://DOI.ORG/ 10.1039/C7FOOO832E
Widen, S. C. y Russell, J. A. (2010). Differentiation in preschooler's categories

emotion. Emotion, 10(5), 651-661. HTTPs:// DOI.ORG/10.1037/A0019005

Yih, J., Uusberg, A., Taxer, J. L. y Gross, J. J. (2018). Better together: a unified perspective on appraisal and emotion regulation. Cognition and Emotion, 33(1), 41-47. HTTPS://DOI.ORG/10.1080/ 02699931.2018 .1504749

Yuen, E. Y., Liu, W., Karatsoreos, I. N., Feng, J., McEwen, B. S. y Yan, Z. (2009). Acute stress enhances glutamatergic transmission in prefrontal cortex and facilitates working memory. Proceedings of the National Academy of Sciences, 106(33), 14075-14079. HTTPS://DOI.ORG/10.1073/ 